\title{
The storage of tetanus vaccine in accident and emergency departments: a postal survey
}

\author{
J. D. HOWELL \& N. G. KIRBY
}

Accident and Emergency Department, Guy's Hospital, St Thomas Street, London SE1 9RT

\section{SUMMARY}

The aim of this study was to assess the quality of storage of tetanus vaccine in accident and emergency (A\&E) departments and also of the awareness of Department of Health guidelines. A postal questionnaire was sent to 50 randomly selected major A\&E departments in the British Isles, enquiring about awareness of Department of Health guidelines (Department of Health, 1990).

Forty (80\%) A\&E departments responded. Only 14 were aware of the Department of Health guidelines and in only 18 was there a member of staff taking responsibility for vaccine storage.

The study found that safe storage of vaccine, and therefore guarantee of efficacy, is not occurring in the majority of $A \& E$ departments. Unnoticed failure of refrigerators could be exposing patients to the risk of tetanus infection.

\section{INTRODUCTION}

A large storage refrigerator in Guy's Hospital Pharmacy had recorded a very low temperature and possibly frozen a batch of vaccine, this had to be withdrawn and returned to the manufacturer for potency testing. This alerted the authors to the danger of this problem occurring in departmental refrigerators. As a result temperature monitoring was introduced at Guy's Hospital and it was decided to investigate the practices of other A\&E departments.

$A \& E$ departments are one of the main sources of tetanus toxoid booster for the general public. The A\&E department at Guy's Hospital administers approximately 50 doses each week. This vaccine must be stored at suitable temperatures in order to maintain its potency. Department of Health guidelines exist in order to ensure that these temperatures are maintained (Department of Health, 1990). Tetanus vaccine should be stored at between 2 and $8^{\circ} \mathrm{C}$. Previous research (Hunter, 1989; Thakker \& Woods, 1992) has shown storage refrigerators in general practice and 
health centres to be unreliable in maintaining this degree of cooling; either warming or freezing the vaccine. No previous studies looking at this problem in A\&E departments, were found.

\section{SUBJECTS AND METHODS}

A fully confidential questionnaire was sent to 50 major (i.e. with a consultant in A\&E medicine) A\&E departments within the British Isles. These were chosen at random from a directory of hospitals with acute services. The questionnaire was addressed to the senior sister of the department. A covering letter ensuring anonymity and explaining the nature of the study was enclosed with a reply envelope. It was not possible to follow up non-respondents.

\section{RESULTS}

Forty completed questionnaires were received, ( $80 \%$ response rate). The results are displayed in Table 1 . Of the 40 departments responding, only $45 \%$ had a member of staff responsible for vaccine storage. In those that did, the responsibility usually fell upon pharmacists $(20 \%)$ or nursing staff $(20 \%)$ (Fig. 1).

The majority of responding departments had no departmental policy of their own concerning storage $(70 \%)$. Of those that did, only one had formed a plan of action in the event of refrigerator failure.

Only one departmental fridge had no thermometer, and the majority of fridges had external temperature indicators $(88 \%)$. External thermometers are very rarely of the maximum/minimum variety. Only two responding departments kept any sort of record of the storage temperatures of their fridges.

The majority of fridges were also used for the storage of other medicines and blood bottles (Fig. 2). Of respondents, 35\% were aware of Department of Health guidelines for vaccine storage.

Table 1. Results of survey into the storage of tetanus vaccine in accident and emergency departments

\begin{tabular}{lrr}
\hline & Yes & No \\
\hline Is there a trained member of staff responsible & & \\
for the storage refrigerator? & 9 & 31 \\
Are there departmental guidelines on storage? & 5 & 35 \\
Do you have a thermometer on the outside of & & \\
$\quad$ your fridge? & 35 & 6 \\
Do you have a thermometer on the inside? & 10 & 30 \\
Is it of the max/min type? & 3 & 7 \\
Are you aware of Department of Health & & \\
$\quad$ guidelines? & 14 & 26 \\
\hline
\end{tabular}




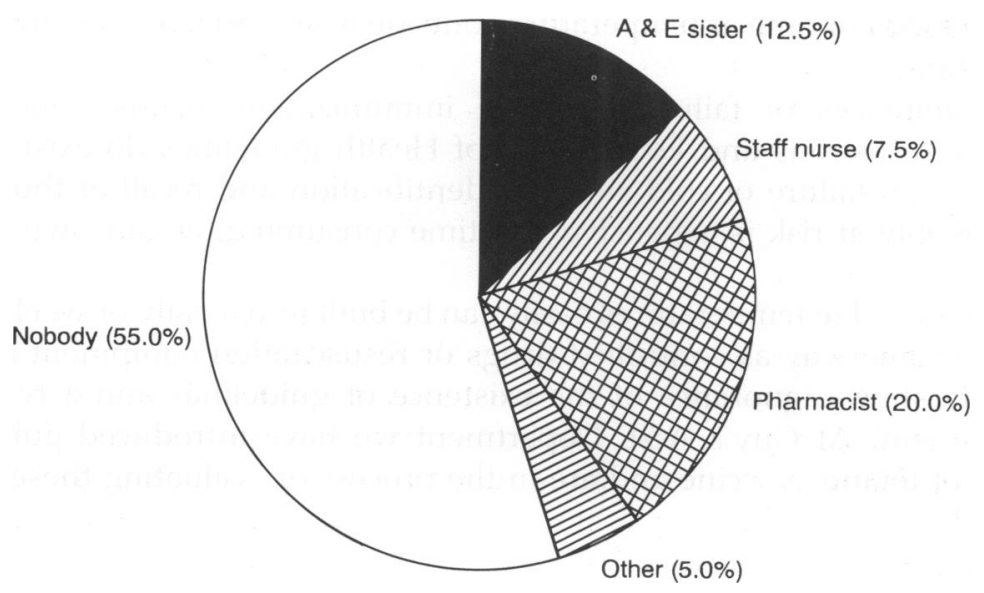

Fig. 1. Responsibility for A\&E fridges.

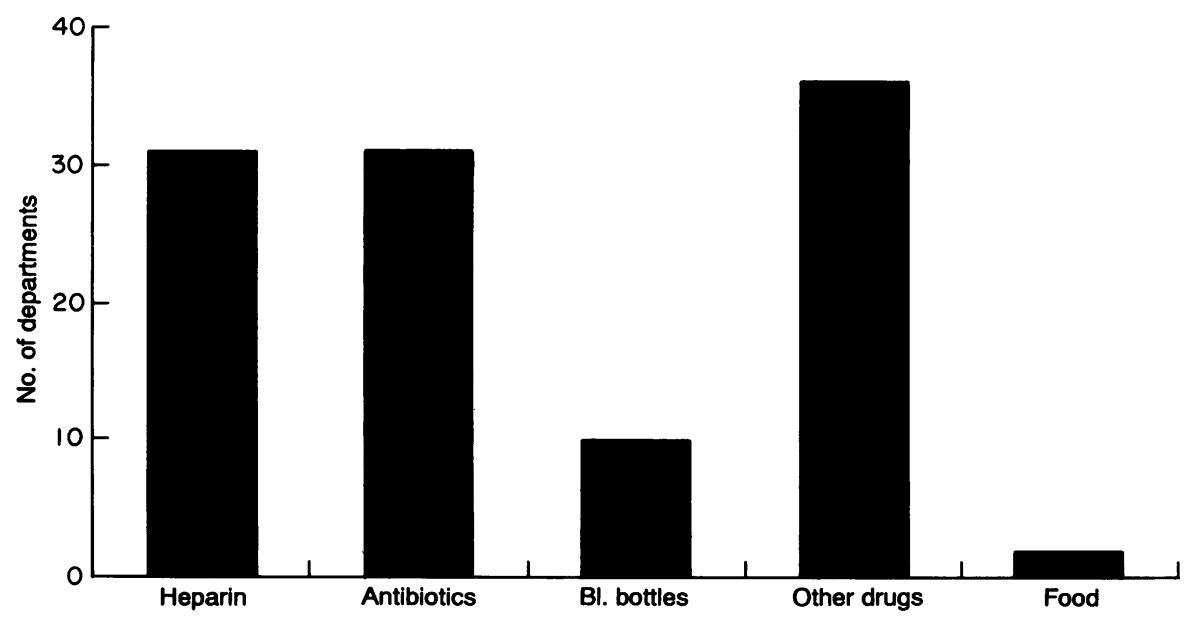

Fig. 2. Use of A\&E fridges.

\section{DISCUSSION}

Improper storage of tetanus vaccine does affect its potency; a World Health Organization (1980) study noted a significant decrease in potency after storage at $-30^{\circ} \mathrm{C}$ for $12 \mathrm{~h}$. Samples stored at between +4 and $-20^{\circ} \mathrm{C}$ had a less significant decrease. Relative to pertussis vaccine for instance tetanus toxoid seems to be fairly hardy; although the effect of temperature on vaccines is cumulative and in those departments with a slow turnover of vaccine or those who store large quantities at a time the risk of potency being affected is greater. Tetanus toxoid retains its potency for $72 \mathrm{~h}$ after storage at room temperature but no data are available concerning storage 
for longer periods of time at temperatures outside $4-8^{\circ} \mathrm{C}$. (Evans Medical, personal communication).

The consequences of failure in active immunization against tetanus would obviously be disastrous and Department of Health guidelines do exist to prevent this. Following a failure of cold storage, identification and recall of those patients who are possibly at risk is expensive and time consuming, as our own experience bore out.

Recording of fridge temperatures easily can be built into a daily or weekly routine, in much the same way as controlled drugs or resuscitation equipment is checked.

This study shows ignorance of the existence of guidelines and a reluctance to implement them. At Guy's A\&E Department we have introduced guidelines for the storage of tetanus vaccine and are in the process of evaluating these at present (Appendix 1).

\section{ACKNOWLEDGEMENTS}

The authors would like to thank Mr Nadeem Nayeem for his advice and help, Dr Joneleit, and all who participated in the survey.

\section{REFERENCES}

Department of Health Joint Committee on Vaccination and Immunisation (1990) Immmunisation Against Infectious Disease. HMSO, London.

Hunter S. (1989) Storage of vaccines in general practice British Medical Journal 299, 661-662.

Thakker Y. \& Woods S. (1992) Storage of vaccines in the community: weak link in the cold chain? British Medical Journal 304, 756-758.

World Health Organization (1980) Expanded programme on immunisation; the effects of freezing on the appearance, potency, and toxicity of adsorbed and unadsorbed DPT vaccines. Weekly Epidemiological Research 55, 385-389, 396-398.

\section{APPENDIX 1}

Proposed guidelines for the storage of tetanus vaccine in Guy's Hospital AEE Department

(1) The vaccine will be stored in one refrigerator containing a maximum/minimum thermometer.

(2) The $\mathrm{max} / \mathrm{min}$ temperature will be read once a week on a weekday by the senior nurse working at that time. A record of these temperatures will be kept in a log book kept with the thermometer. After recording the $\max / \mathrm{min}$ thermometer must be reset.

(3) If the max/min temperatures are noted to lie outside the +2 to $+8^{\circ} \mathrm{C}$ range then the sister on duty or the departmental Registrar should be alerted to this fact.

If the vaccine has been subject to temperatures below $0^{\circ} \mathrm{C}$ it should be replaced with new stocks and returned to the pharmacy.

The new vaccine should be stored in an alternative refrigerator until the thermostat can be reset or the fridge serviced. 
The pharmacy should be alerted to the fact that the potency of the vaccine may be reduced, it can then be returned to the manufacturer for testing and recall of patients can be started if this is thought necessary.

(4) During defrosting of the fridge the vaccine must be placed in another refrigerator. The $\mathrm{max} / \mathrm{min}$ thermometer must also be reset after defrosting. 